\title{
Abordagem Terapêutica nas Infeções por Staphylococcus aureus Resistentes à Meticilina
}

\section{Treatment Approach of Methicillin-Resistant Staphylococcus aureus Infections}

Ana Freitas ${ }^{1}$, Isabel Marcos ${ }^{1}$, Luísa Fontes ${ }^{2}$, Sílvia Martins ${ }^{1}$

\section{RESUMO}

As infeções provocadas por Staphylococcus aureus resistentes à meticilina são hoje em dia um problema com grande impacto a nível mundial, que podem levar a internamentos prolongados e a um aumento dos custos associados aos cuidados de saúde. Nesse sentido, este artigo faz uma breve revisão sobre o Staphylococcus aureus resistente à meticilina e os seus mecanismos de resistência ao longo dos tempos, bem como da terapêutica recomendada para o tratamento das infeções mais encontradas na prática clínica.

PALAVRAS-CHAVE: Farmacorresistência Bacteriana Múltipla; Infeções Estafilocócicas/tratamento; Staphylococcus aureus Resistente à Meticilina

\section{ABSTRACT}

Infections caused by methicillin-resistant Staphylococcus aureus are now a problem with great impact worldwide, which can lead to prolonged hospitalization and increased costs associated with health care. Therefore, this article summarizes the methicillin-resistant Staphylococcus aureus and its mechanisms of resistance, as well as the recommended therapy for the treatment of infections most commonly found in clinical practice.

KEYWORDS: Drug Resistance Multiple Bacterial; Methicillin-Resistant Staphylococcus aureus; Staphylococcal Infections/ drug therapy 


\section{INTRODUÇÃO}

O Staphylococcus aureus é um microrganismo comensal encontrado frequentemente na pele e mucosas dos seres humanos. Pode, no entanto, tornar-se patogénico e causar uma grande variedade de infeções. ${ }^{1}$

A incidência de novas infeções por Staphylococcus aureus, particularmente pelas estirpes Staphylococcus aureus resistentes à meticilina, tem aumentado consideravelmente nos últimos anos por todo o mundo. A crescente resistência aos antibióticos aliada à forte capacidade de colonização e evasão ao sistema imunitário pelo Staphylococcus aureus resistente à meticilina (MRSA), têm contribuído para a sua disseminação não só nos hospitais, mas também na comunidade. A infeção por MRSA está, por isso, associada a elevados índices de morbilidade e mortalidade, representando um elevado custo para os sistemas de saúde. ${ }^{2}$

\section{CONTEXTUALIZAÇÃO HISTÓRICA DO} STAPHYLOCOCCUS AUREUS RESISTENTE À METICILINA E SUAS RESISTÊNCIAS

A descoberta da penicilina em 1940 veio mudar o paradigma das infeções, especialmente das infeções provocadas por Staphylococcus aureus. Porém, o início da sua utilização culminou também com o aparecimento das primeiras estirpes resistentes produtoras de $\beta$-lactamases, tornando a penicilina ineficaz. No fim da década de 60 , mais de $80 \%$ das estirpes isoladas apresentavam resistência à penicilina. ${ }^{3-5}$

Para dar resposta à situação, surge em 1960 um novo antibiótico, denominado meticilina, capaz de resistir à ação das $\beta$-lactamases. No entanto, em menos de um ano são também isoladas estirpes resistentes à meticilina, conhecidas por Staphylococcus aureus resistentes à meticilina (MRSA), dando origem à expressão multirresistência. ${ }^{4-6}$

A resistência do MRSA aos antibióticos tem sido desenvolvida por mutações nos seus genes ou pela aquisição de genes de resistência de outras bactérias. A resistência à meticilina é conferida pelo gene mecA, o qual codifica uma proteína de ligação à penicilina (PPB2a) com baixa afinidade para os antibióticos $\beta$-lactâmicos. ${ }^{4,5}$

Apesar de inicialmente estarem limitadas aos hospitais, as infeções causadas por MRSA começaram também a surgir na comunidade, levando à distinção entre MRSA adquirida no hospital (HA-MSRA) e adquirida na comunidade (CA-MRSA). ${ }^{6}$

Os primeiros relatos de infeções por CA-MRSA ocorreram na década de 90 na Austrália e nos Estados Unidos. A partir de então, a emergência desta nova estirpe

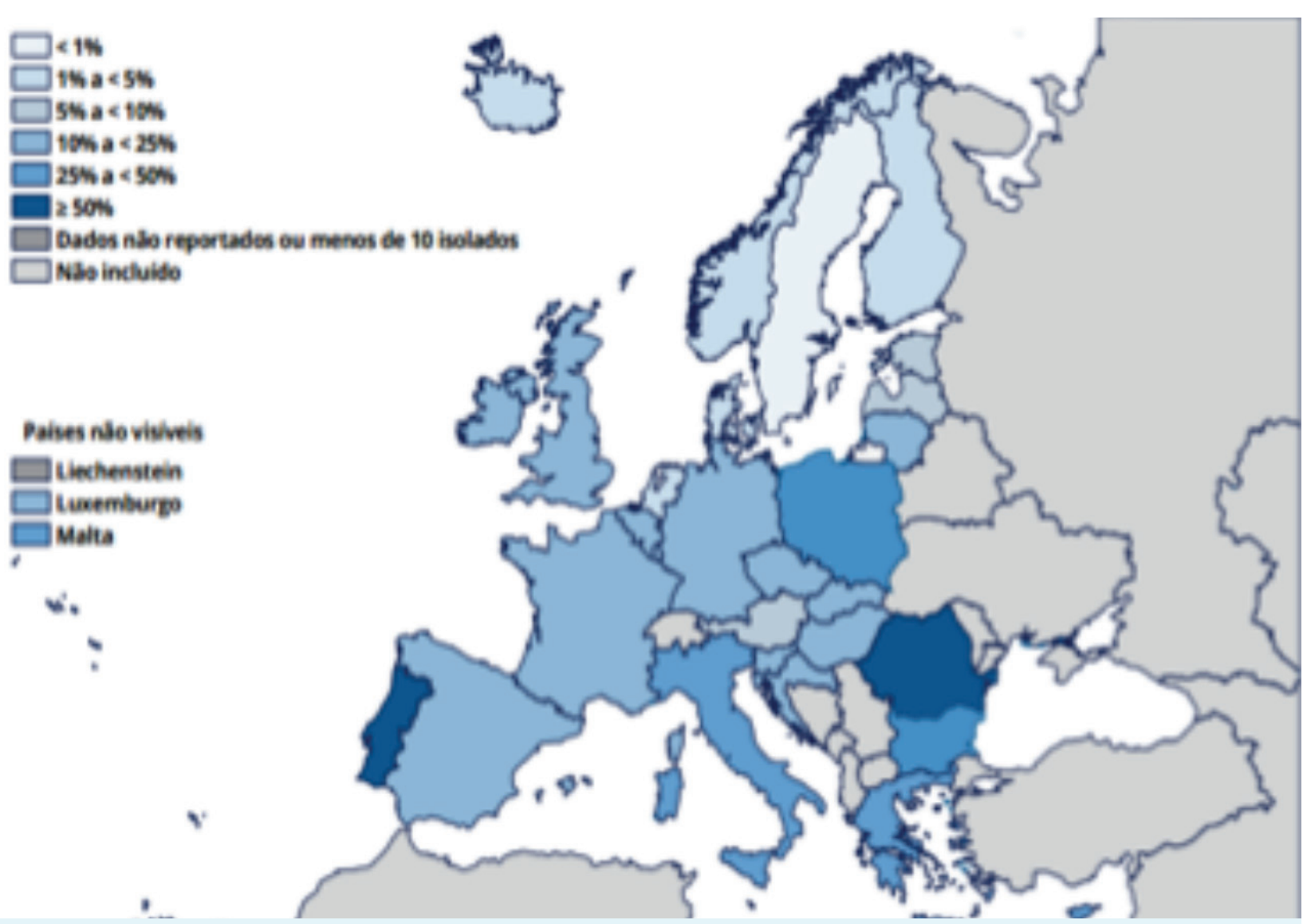

FIGURA 1. Proporção de Staphylococcus aureus isolados na Europa, dados referentes a 2012. Adaptado de European Centre for Disease Prevention and Control. 
tornou-se numa questão de saúde pública mundial. Ao contrário da estirpe HA-MRSA, a estirpe CA-MRSA não é encontrada em ambientes nosocomiais e surge como resultado de mutações nas bactérias Staphylococcus aureus sensíveis à meticilina (MSSA) presentes na comunidade. As principais diferenças entre estas duas estirpes residem nas suas manifestações clínicas e no perfil de resistência aos antibióticos. A estirpe CA-MRSA está geralmente associada a infeções da pele e tecidos moles, e caracteriza-se por uma maior sensibilidade a antibióticos não $\beta$-lactâmicos, tais como clindamicina, gentamicina, trimetroprim-sulfametoxazol e vancomicina. ${ }^{1-4}$

Segundo as estatísticas do European Centre for Disease Prevention and Control, Portugal apresenta um dos níveis mais elevados de isolados MRSA da Europa. A taxa de resistência foi crescente até 2011, ano em que atingiu o seu valor máximo, 54,6\%. A partir de 2012 verificou-se uma melhoria da percentagem, fixando-se em 47,4\% em 2014 (dados disponíveis mais recentes, Fig. 1).,78

Perante um quadro de diagnóstico de uma infeção por MRSA, é necessário a instituição de terapêutica antibiótica, que consoante os resultados laboratoriais, pode posteriormente ser adaptada. Nesta revisão da literatura irá ser abordado de seguida, a antibioterapia recomendada para as infeções mais encontradas pelos clínicos, nomeadamente, infeções da pele e tecidos moles, infeções ósseas e articulares e pneumonias.

\section{INFEÇÕES DA PELE E TECIDOS MOLES POR STAPHYLOCOCCUS AUREUS RESISTENTES À METICILINA}

A antibioterapia no caso de uma infeção da pele e tecidos moles está indicada quando o clínico está perante um quadro de doença grave ou que envolva vários locais de infeção, se existe um quadro de evolução rápida associada a celulite, sinais ou sintomas de doença sistémica e se a localização do abcesso dificulta a sua drenagem. É importante também ter em conta as comorbilidades do doente, e se este se encontra sob tratamento com imunossupressores. ${ }^{?}$

Se o quadro de infeção da pele e tecidos moles for indicativo de MRSA da comunidade é recomendada a cobertura empírica em ambulatório, enquanto se aguardam os resultados laboratoriais. São opções terapêuticas por via oral, a clindamicina, o trimetroprim-sulfametoxazol, a doxiciclina ou o linezolide. $\bigcirc$ uso da rifampicina não se encontra indicado nestes casos como tratamento isolado ou adjuvante. 9,10

Para doentes em meio hospitalar com uma infeção da pele que envolva zonas mais profundas das partes mo- les, infeções de feridas provenientes de uma cirurgia, abcessos, celulites ou úlceras infetadas, é importante o clínico considerar o tratamento empírico com cobertura para MRSA, introduzindo como terapêutica antibiótica a vancomicina por via intravenosa (IV), o linezolide, por via oral ou IV, a daptomicina IV, ou a clindamicina IV ou oral.?

\section{INFEÇÕES ÓSSEAS E ARTICULARES POR STAPHYLOCOCCUS AUREUS RESISTENTES À METICILINA}

No caso de se tratar de uma infeção óssea (osteomielite), e sempre que seja necessário e viável, existem dois pontos essenciais para o tratamento, são eles, o desbridamento cirúrgico e a drenagem dos abcessos. O clínico pode escolher entre iniciar o tratamento por via oral ou IV, adaptando à situação clínica do doente. Os antibióticos recomendados são a vancomicina IV, a daptomicina IV, o trimetroprim-sulfametoxazol oral em combinação com a rifampicina, o linezolide IV ou oral ou a clindamicina IV ou oral. Doentes que apresentem bacteremia, é de salientar a importância de iniciar rifampicina apenas após o fim do quadro da bacteremia. Está recomendado uma duração mínima de 8 semanas de tratamento, que pode ser prolongado no caso de se tratar de uma infeção crónica, ou se não foi efetuado desbridamento. O clínico pode assim escolher prolongar o tratamento entre um a três meses, recorrendo à terapêutica com rifampicina em combinação com um outro antibiótico sensível à bactéria.?

Na artrite séptica os antibióticos recomendados são os mesmos que nos casos de osteomielite, mas a duração de antibioterapia recomendada é entre três e quatro semanas.?

Nas infeções osteoarticulares por MRSA devido a próteses com início menos de dois meses após a intervenção cirúrgica, ou no caso de uma infeção aguda numa prótese articular estável com uma duração dos sintomas inferior a três ou menos semanas, iniciar a terapêutica por via IV de acordo com o tratamento recomendado para a osteomielite com a adição da rifampicina por um período de duas semanas.?

\section{PNEUMONIAS POR STAPHYLOCOCCUS AUREUS RESISTENTES À METICILINA}

O MRSA é um potencial agente para vários casos de pneumonia adquirida na comunidade, ou pneumonias nosocomiais, como já foi descrito acima.

Perante uma situação de necessidade de internamento numa unidade de cuidados intensivos, a presença de empiema, ou de infiltrados necrozantes ou cavitários é recomendado iniciar empiricamente o tratamento para 
MRSA. É muito importante a colheita para cultura, antes de iniciar o tratamento empírico.?

De entre as opções terapêuticas, a vancomicina ou o linezolide são os antibióticos recomendados para os casos de pneumonia por MRSA. O linezolide por ter uma boa distribuição no parênquima pulmonar surge como uma alternativa à vancomicina. ${ }^{9,11}$

Sabe-se ainda, que as infeções por MRSA adquiridas na comunidade apresentam mais sensibilidade aos antimicrobianos que os MRSA adquiridos em infeções nosocomiais. $^{12}$

\section{VANCOMICINA VERSUS LINEZOLIDE - INFEÇÕES POR STAPHYLOCOCCUS AUREUS RESISTENTES À METICILINA}

A vancomicina, antibiótico administrado por via IV, à exceção das infeções por Clostridium difficile, que é administrada por via oral, tem sido o grande antibiótico utilizado no tratamento para infeções por MRSA. O seu uso pode ser limitado pela sua toxicidade ocorrendo necessidade de ajuste posológico de acordo com os níveis plasmáticos. Com o aparecimento da resistência à vancomicina, o linezolide surgiu como uma alternativa para as infeções por MRSA, sendo o primeiro antibiótico pertencente à classe das oxazolidinonas aprovado pela Food and Drug Administration (FDA), para o tratamento de pneumonias adquiridas na comunidade e pneumonias nosocomiais, e para infeções da pele e tecidos moles por MRSA. Este antibiótico atua, inibindo a síntese proteica, ligando-se ao ribossoma bacteriano, impedindo a formação do complexo de iniciação 70s, necessário para o processo de transcrição. ${ }^{13,14}$

A disponibilidade de uma formulação oral de linezolide revelou uma utilização maior deste antibiótico, permitindo a continuação do tratamento dos doentes em regime de ambulatório. ${ }^{15}$

Avaliou-se num estudo que os doentes hospitalizados com infeção conhecida ou suspeita por MRSA, em casos de infeções da pele e tecidos moles e pneumonia, o uso do linezolide em comparação com a vancomicina foi clinicamente e também microbiologicamente eficaz. ${ }^{13}$

\section{NOVOS ANTIBACTERIANOS NO TRATAMENTO POR STAPHYLOCOCCUS AUREUS RESISTENTES À METICILINA}

Atualmente, as infeções resistentes são descobertas após tratamentos consecutivos que se verificam ineficazes. Neste sentido, surge com o aumento das resistências, uma necessidade cada vez maior da investigação de novos antibacterianos.
Nos últimos anos foram aprovados novos antibióticos para o tratamento de infeções por MRSA, como a oritavancina, um glicopéptido administrado por via intravenosa e indicado para o tratamento de infeções bacterianas agudas cutâneas e das estruturas cutâneas, contra bactérias gram-positivas. ${ }^{16}$

Uma nova oxazolidinona, o tedizolide, com indicação para infeções da pele e tecidos moles causadas por Staphylococcus aureus (incluindo MRSA e MSSA) foi também aprovado pela FDA, encontrando-se ainda, este antibiótico sob investigação para o tratamento de pneumonias nosocomiais. ${ }^{17}$

Uma nova cefalosporina de largo espectro, a ceftarolina, foi também aprovada pela FDA, para o tratamento de infeções da pele e tecidos moles e pneumonias adquiridas na comunidade causadas pelo MRSA. ${ }^{18}$

Em processo de investigação está uma nova fluoroquinolona, a delafloxacina, com indicação para o tratamento de infeções agudas da pele e tecidos moles. ${ }^{19}$

\section{CONCLUSÃO}

O desenvolvimento dos mecanismos de resistência do Staphylococcus aureus tem indicado estar intimamente relacionado com a má prática de utilização dos antibióticos. Dessa forma, devem ser adotadas pelos profissionais de saúde medidas que levem à diminuição do aparecimento de novas resistências, passando pela sensibilização dos doentes para o cumprimento da posologia e do tempo de tratamento estabelecido.

CONFLITOS DE INTERESSE: Os autores do presente artigo de revisão declaram a inexistência de conflitos de interesse na realização do mesmo.

FONTES DE FINANCIAMENTO: Não existem fontes de financiamento para a execução deste artigo de revisão.

\section{REFERÊNCIAS}

1. Gordon R, Lowy F. Pathogenesis of methicilin-resistant Staphylococcus aureus infection. Clin Infect Dis. 2008;46:350-9.

2. Naber C. Staphylococcus aureus bacteremia: epidemiology, pathophysiology and management strategies. Clin Infect Dis. 2009;48:231-7.

3. Tan S, Tatsumura Y. Alexander Fleming (1881-1955): Discoverer of penicillin. Singapore Med J.2015;56:366-7.

4. Santos A, Santos D, Freitas C, Ferreira B, Afonso I, Rodrigues C, et al. Staphylococcus aureus: visitando uma cepa de importância hospitalar. J Bras Patol Med Lab. 2007;43:413-23.

5. Lowy F. Antimicrobial resistance: the example of Staphylococcus aureus. J Clin Invest. 2003;111:1265-73.

6. Gelatti L, Becker A, Bonamigo R, Azevedo P. Staphylococcus aureus resistentes à meticilina: disseminação emergente na comunidade. An Bras Dermatol. 2009;84:501-6. 
7. Prevenção e Controlo de Infeções e de Resistência aos Antimicrobianos em números - 2014, Programa de Prevenção e Controlo de Infeções e de Resistência aos Antimicrobianos; [consultado 29 setembro 2016]. Disponível em: http://www. dgs.pt.

8. Antimicrobial resistance surveillance in Europe 2014. [consultado 29 setembro 2016]. Disponível em: http://www.ecdp. europa.eu.

9. Liu C, Bayer A, Cosgrove S, Daum R, Fridkin S, Gorwitz R, et al. Clinical Practice Guidelines by the infectious diseases society of america for the treatment of methicillin-resistant Staphylococcus aureus infections in adults and children. Clin Infect Dis. 2011;52:e18-55.

10. Lowy F. Methicillin-resistant Staphylococcus aureus (MRSA) in adults: Treatment of skin and soft tissue infections. 2016. [consultado 24 setembro 2016]. Disponível em: https://www. uptodate.com/contents/methicillin-resistant-staphylococcus-aureus-mrsa-in-adults-treatment-of-skin-and-soft-tissue-infections.

11. File T. Treatment of community-acquired pneumonia in adults who require hospitalization. 2016. [consultado 24 setembro 2016]. Disponível em: https://www.uptodate.com/contents/ treatment-of-community-acquired-pneumonia-in-adults-who-require-hospitalization.

12. Rubinstein E, Kollef MH, Nathwani D. Pneumonia caused by methicillin-resistant Staphylococcus. Clin Infect Dis. 2008;5:378.
13. Watkins R, Lemonovich T, File T. An evidence-based review of linezolid for the treatment of methicillin-resistant Staphylococcus aureus (MRSA): place in therapy. Core Evid. 2012; 7:131-43.

14. Diekema D, Jones R. Oxazolidinones. drugs. Berlin: Adis Press;2000.

15. Gorchynski J, Rose J. Complications of MRSA treatment: linezolid-induced myelosuppression presenting with pancytopenia. West J Emerg Med. 2008;9:177-8.

16. Brade K, Rybak J, Rybak M, Oritavancin: a new lipoglycopeptide antibiotic in the treatment of gram-positive infections. Infect Dis Ther. 2016:5:1-15.

17. Rybak J, Roberts K. Tedizolid phosphate: a next-generation oxazolidinone. Infect Dis Ther. 2015;4:1-14.

18. Vazquez A, Maggiore C, Cole P, Smith A, Jandourek A, Friedland $\mathrm{H}$, et al. Ceftaroline fosamil for the treatment of Staphylococcus aureus bacteremia secondary to acute bacterial skin and skin structure infections or community-acquired bacterial pneumonia. Infect Dis Clin Pract. 2015;23:39-43.

19. Bassetti M, Della Siega P, Pecori D, Scarparo C, Righi E. Delafloxacin for the treatment of respiratory and skin infections. Expert Opin Investig Drugs. 2015;24:433-42. 